\title{
Public health fallout from Japanese quake
}

A "culture of coverup" and inadequate cleanup efforts have combined to leave Japanese people exposed to "unconscionable" health risks nine months after last year's meltdown of nuclear reactors at the Fukushima Daiichi power plant, health experts say.

Although the Japanese government has declared the plant virtually stable, some experts are calling for evacuation of people from a wider area, which they say is contaminated with radioactive fallout.

They're also calling for the Japanese government to reinstate internationally approved radiation exposure limits for members of the public and are slagging government officials for "extreme lack of transparent, timely and comprehensive communication.'

But temperatures inside the Fukushima power station's three melted cores have achieved a "cold shutdown condition," while the release of radioactive materials is "under control," according to the International Atomic Energy Agency (www.iaea.org/news center/news/2011/coldshutdown.html). That means government may soon allow some of the more than 100000 evacuees from the area around the plant to return to their homes. They were evacuated from the region after it was struck with an 8.9 magnitude earthquake and a tsunami on Mar. 11, 2011.

Although the potential for further explosions with substantial releases of radioactivity into the atmosphere is certainly reduced, the plant is still badly damaged and leaking radiation, says Tilman Ruff, chair of the Medical Association for Prevention of War (Australia), who visited the Fukushima prefecture in August 2011. "There are major issues of contamination on the site. Aftershocks have been continuing and are expected to continue for many months, and some of those are quite large, potentially causing further damage to structures that are already unstable and weakened. And we know that

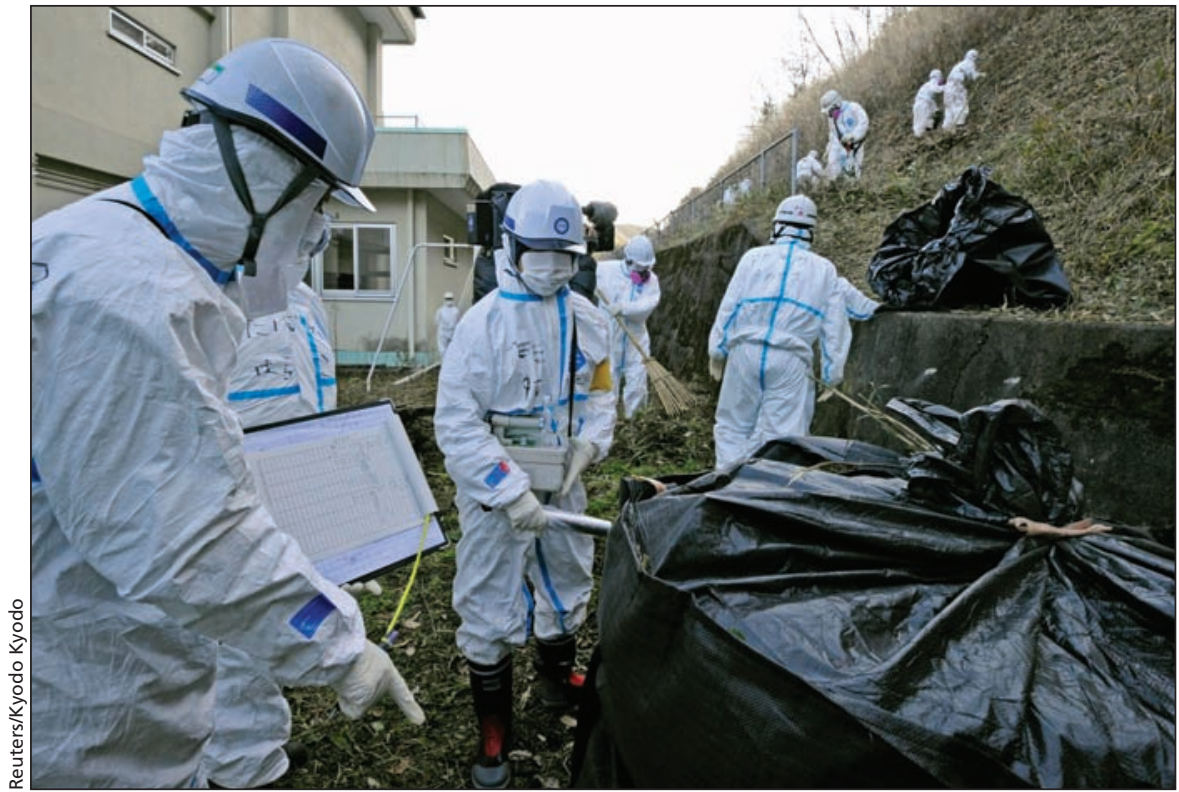

Workers decontaminate around an elementary school in the town of Katsurao, Japan near the tsunami-crippled Fukushima Daiichi nuclear power plant in Fukushima.

there's about 120000 tons of highly contaminated water in the base of the plant, and there's been significant and ongoing leakage into the ocean."

The full extent of contamination across the country is even less clear, says Ira Helfand, a member of the board of directors for Physicians for Social Responsibility. "We still don't know exactly what radiation doses people were exposed to [in the immediate aftermath of the disaster] or what ongoing doses people are being exposed to. Most of the information we're getting at this point is a series of contradictory statements where the government assures the people that everything's okay and private citizens doing their own radiation monitoring come up with higher readings than the government says they should be finding."

Japanese officials in Tokyo have documented elevated levels of cesium - a radioactive material with a halflife of 30 years that can cause leukemia and other cancers - more than 200 kilometres away from the plant, equal to the levels in the 20-kilometre exclusion zone, says Robert Gould, another member of the board of directors for Physicians for Social Responsibility.

International authorities have urged Japan to expand the exclusion zone around the plant to 80 kilometres but the government has instead opted to "define the problem out of existence" by raising the permissible level of radiation exposure for members of the public to 20 millisieverts per year, considerably higher than the international standard of one millisievert per year, Gould adds.

This "arbitrary increase" in the maximum permissible dose of radiation is an "unconscionable" failure of government, contends Ruff. "Subject a class of 30 children to 20 millisieverts of radiation for five years and you're talking an increased risk of cancer to the order of about 1 in 30, which is completely unacceptable. I'm not aware of any other government in recent decades that's been willing to accept such a high level of radiation-related risk for its population."

Following the 1986 nuclear disaster at the Chernobyl nuclear power plant in Ukraine, "clear targets were set so that anybody anticipated to receive more 
than five millisieverts in a year were evacuated, no question," Ruff explains. In areas with levels between one and five millisieverts, measures were taken to mitigate the risk of ingesting radioactive materials, including bans on local food consumption, and residents were offered the option of relocating. Exposures below one millisievert were still considered worth monitoring.

In comparison, the Japanese government has implemented a campaign to encourage the public to buy produce from the Fukushima area, Ruff added. "That response [in Chernobyl] 25 years ago in that much less technically sophisticated, much less open or democratic context, was, from a public health point of view, much more responsible than what's being done in modern Japan this year."

Were Japan to impose similar strictures, officials would have to evacuate some 1800 square kilometres and impose restrictions on food produced in another 11100 square kilometres, according to estimates of the contamination presented by Dr. Kozo Tatara for the Japan Public Health Association at the American Public Health Association's 139th annual meeting and exposition in November 2011 in Washington, District of Columbia.

"It's very difficult to persuade people that the level [of exposure set by the government] is okay," Tatara told delegates to the meeting. He declined requests for an interview.

The Japanese government is essentially contending that the higher dose is "not dangerous," explains Helfand. "However, since the accident, it's become clear the Japanese government was lying through its teeth, doing everything it possibly could to minimize public concern, even when that meant denying the public information needed to make informed decisions, and probably still is."

"It's now clear they knew within a day or so there had been a meltdown at the plant, yet they didn't disclose that for weeks, and only with great prodding from the outside," Helfand adds. "And at the same moment he was assuring people there was no public health disaster, the Prime Minister now concedes that he thought Tokyo would have to be evacuated but was doing nothing to bring that about."

Ruff similarly charges that the government has mismanaged the file and provided the public with misinformation. As an example, he cites early reports that stable iodine had been distributed to children and had worked effectively, when, "in fact, iodine wasn't given to anyone."

Public distrust is at a level that communities have taken cleanup and monitoring efforts into their own hands as the government response to the crisis has been "woefully inadequate" and officials have been slow to respond to public reports of radioactive hotspots, Gould says. "That's led to the cleanup of some affected areas, but there are also reports of people scattering contaminated soil willy-nilly in forests and areas surrounding those towns."

"In some places, you can see mounds of contaminated soil that have just been aggregated under blue tarps," he adds.

Even with government assistance, there are limits to the decontamination that can be achieved, explains Helfand. "What do you do with the stuff? Do you scrape entire topsoil? How far down you have to go? And if you wash down the buildings, what do you do with the waste water?"

As well, Ruff argues the government must examine the provision of compensation for voluntary evacuation from areas outside of the exclusion zone where there are high levels of radioactive contamination. Without such compensation, many families have no option but to stay, he says. "At this point, the single most important public health measure to minimize the health harm over the longterm is much wider evacuation."

The Japanese government did not respond to inquiries. - Lauren Vogel, $C M A J$, with files from Barbara Sibbald, CMAJ

CMAJ 2011. DOI:10.1503/cmaj.109-4083 